\title{
NUMERICAL INVESTIGATION OF NATURAL CONVECTION FOR VERTICAL FLAT PLATE WITH FINS
}

\author{
Sinha..M.K.* and Dash S.K. \\ *Author for correspondence \\ Department of Mechanical Engineering \\ N.I.T,Jamshedpur and I.I.T Kharagpur \\ India \\ E-mail: mrityunjay.nit@gmail.com
}

\begin{abstract}
A finite-volume-based computational study of steady laminar natural convection from a finned isothermal vertical plate with different fin arrays has been carried out to determine the heat transfer augmentation factor with different fin aspect ratio, fin spacing and inclination of fin. Heat transfer behaviors with the fins have been analyzed by examining variations of the local and average Nusselt numbers in twodimensional flow. Four different fin arrays heights $(\mathrm{H}=6$, $12,18,24 \mathrm{~mm})$ and four different angles of inclination $(\theta=$ $\left.45^{\circ}, 60^{\circ}, 75^{\circ}, 90^{\circ}\right)$ are considered.
\end{abstract}

In order to understand the heat transfer characteristics of this problem, a total of 96 cases for each of conductive and nonconductive fins are considered. It is found that significant heat transfer augmentation is obtained for conductive $(20 \%$ higher augmentation factor when the fin aspect ratio is 6 , and angle of inclination is $60^{\circ}$ and pitch-to-length ratio is 0.2 ) and non-conductive fins (10\% higher augmentation factor, at fin aspect ratio of 8 , angle of inclination at $45^{\circ}$ and pitch-tolength ratio at 0.5). A general correlation has been developed to predict the average Nusselt number for fin arrays as a function of different fin configurations.

\section{INTRODUCTION}

Basic understanding of the characteristics of fluid flow and heat transfer from plate-fin heat exchangers is very important to determine optimum heat exchanger configurations, and to find reliable and efficient methods for the cooling of heat exchange devices. Normally such type plate heat exchangers are used in paint shops of car manufacturing units and they are limited to a height of $0.7 \mathrm{~m}$ and at best a temperature difference of $25{ }^{\circ} \mathrm{C}$ exists between the plate and the surroundings where it is expected that the flow around the plate would be laminar $\left(\mathrm{Ra}<10^{9}\right)$ and the heat transfer would be governed by laminar natural convection.
There has been continuous research on improving the efficiency of heat exchange devices using fins involving natural convection. Early experimental work on natural convection in horizontal and vertical fin arrays was conducted by Starner and McManus (1), Welling and Wooldridge (2), Harahap and McManus (3), Jones and Smith (4), Van de pol and Tierney (5), and Bar-Cohen (6). These literatures on fin heat exchange devices in natural convection concern mostly plate fin, although pin fins provide better performance as reported by Sparrow and Vemuri (7), Zografos and Sunderland (8), and Aihara et al (9). Park et al (10) carried out a numerical study of natural convection of heat transfer from plate heat exchanger with staggered pin fin arrays. They utilized a commercial finitevolume CFD code with the sequential linear programming method and weighting method to obtain an optimal design of heat exchangers for a fixed volume.

\section{NOMENCLATURE}

$\begin{array}{ll}\mathrm{A} & {\left[\mathrm{m}^{2}\right]} \\ \mathrm{Gr} & {[-]} \\ & \\ \mathrm{H} & {[\mathrm{mm}]} \\ \mathrm{L} & {[\mathrm{m}]} \\ \mathrm{N} & {[-]} \\ \mathrm{Nu}_{\mathrm{y}} & {[-]} \\ \overline{N u} & {[-]} \\ \mathrm{P} & {[\mathrm{m}]} \\ & \\ \mathrm{Pr} & {[-]} \\ \mathrm{Ra} & {[-]} \\ \mathrm{T} & {[\mathrm{K}]} \\ \mathrm{H} / \mathrm{t} & {[-]} \\ \mathrm{P} / \mathrm{L} & {[-]}\end{array}$

Surface area of the vertical plate Grashof number based on L,

$$
g \beta\left(T_{w}-T_{\infty}\right) L^{3} / v^{2}
$$

Height of the fin

Length of the vertical flat plate

Number of fins

Local Nusselt number

Average Nusselt number

Pitch, center-to-center distance of two consecutive fins

Prandtl number, $v / \alpha$

Raleigh's number

Absolute temperature

Aspect ratio of the fin

Fin spacing 


\begin{tabular}{|c|c|c|}
\hline $\begin{array}{l}\mathrm{c}_{\mathrm{p}} \\
\mathrm{h}\end{array}$ & $\begin{array}{l}{\left[\mathrm{J} / \mathrm{kgK}^{-1}\right]} \\
{\left[\mathrm{W} / \mathrm{m}^{2} \mathrm{~K}^{-1}\right]}\end{array}$ & $\begin{array}{l}\text { fluid specific heat } \\
\text { Local heat transfer coefficient }\end{array}$ \\
\hline $\bar{h}$ & {$\left[\mathrm{~W} / \mathrm{m}^{2} \mathrm{~K}^{-1}\right]$} & Average heat transfer coefficient \\
\hline $\mathrm{k}$ & {$\left[\mathrm{W} / \mathrm{mK}^{-1}\right]$} & Thermal conductivity of fluid \\
\hline $\mathrm{q}$ & {$[\mathrm{W}]$} & Heat transfer rate \\
\hline $\mathrm{t}$ & {$[\mathrm{mm}]$} & Thickness of the fin \\
\hline$\vec{v}$ & {$[\mathrm{~m} / \mathrm{s}]$} & Velocity vector \\
\hline $\mathrm{Y}_{1}$ & {$[\mathrm{~mm}]$} & $\begin{array}{l}\text { Location of fin in span-wise } \\
\text { direction }\end{array}$ \\
\hline
\end{tabular}

\section{Greek}

$\begin{array}{ll}\alpha & {\left[\mathrm{m}^{2} / \mathrm{s}\right]} \\ \beta & {\left[\mathrm{K}^{-1}\right]} \\ \theta & {[\text { degree }]} \\ \mu & {[\mathrm{Pa} \cdot \mathrm{s}]} \\ \nu & {\left[\mathrm{m}^{2} / \mathrm{s}\right]} \\ \rho & {\left[\mathrm{kg} / \mathrm{m}^{3}\right]}\end{array}$

Thermal diffusivity

Thermal coefficient of expansion

Angle of inclination

Dynamic viscosity of fluid

Kinematic viscosity of fluid

Density

\section{Subscripts}

$\begin{array}{ll}\text { Comp } & \text { computed } \\ \text { Max } & \text { maximum } \\ \text { Pred } & \text { predicted } \\ \text { Pp } & \text { plain plate } \\ \text { w } & \text { wall } \\ \infty & \text { surrounding } \\ \text { i } & \text { x-component } \\ \text { j } & \text { y-component }\end{array}$

\section{PHYSICAL DESCRIPTION OF THE PROBLEM}

The schematic diagram of a heated vertical flat plate with fins is shown in Fig 1. The co-ordinate system in which the plate is fixed and the computation would be carried out is also shown in the Fig 1. The plate is fixed with some fins which have a height of $\mathrm{H}$, thickness of $\mathrm{t}$ and fin separation pitch between two consecutive fins is $\mathrm{P}$. The plate length is $\mathrm{L}$ and it has a constant temperature of $\mathrm{T}_{\mathrm{w}}$. The objective is to find out the net heat transfer from the plate in laminar natural convection and hence determine the average Nusselt number for the plate and finally predict the heat transfer augmentation factor as a function of fin configuration. If a heat transfer augmentation factor for different fin configuration is known then fins can occasionally be used on the plates or even permanently without adding any extra cost to the device.

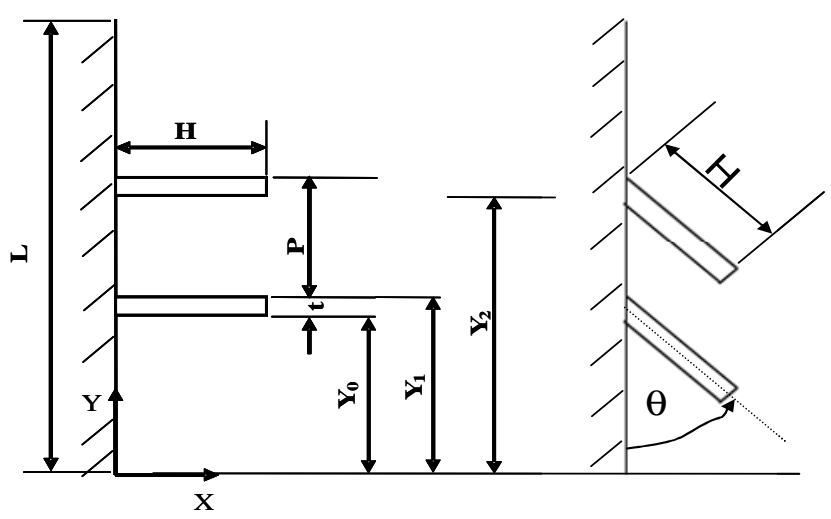

Fig.1 Schematic diagram of the heated plate with straight and inclined fins

\section{Mathematical Formulation}

In order to solve the flow and the temperature field around the finned plate we would use the Navier-Stokes equation with buoyancy driven terms in the y-momentum equation along with the energy equation which will solve for the temperature field in the domain as well as in the fin (provided it is conductive). If the fin is non-conductive $(\mathrm{k}=$ 0 ) we will simply take out the non-conductive portion of the fin from the computational domain and attach a boundary condition on the surface of the non-conductive fin.

The assumptions in the mathematical formulation and the solution process are the following based on which the governing equations are written.

1. The flow field is steady, laminar and incompressible with the fluid stresses being Newtonian.

2. The properties of the fluid (air, its $\mu, \mathrm{k}, \mathrm{c}_{\mathrm{p}}$ and $\rho$ ) are kept constant at free stream conditions in all the equations except for the density of air, $\rho$, in the buoyancy term of the momentum equation only where it is assumed to be a function of temperature so that the buoyancy force can be induced in the fluid. The Boussinesq approximation for the buoyancy is not assumed in the present study; rather density of air is taken to be a straight function of temperature through the ideal gas law and is provided as a table to the computing software. The temperature difference between the plate and the surroundings fluid is of the order of $25{ }^{\circ} \mathrm{C}$, so Boussinesq approximation is not used. The computation of density from the ideal gas law is done by assuming the pressure to be atmospheric only since the equipments work in the atmospheric conditions. 
3. Radiation from the plate and from the fin is also neglected because the plate temperature is hardly $25{ }^{\circ} \mathrm{C}$ more than the ambient temperature.

With the above assumptions the governing equations for the flow field and heat transfer around the vertical plate with fins would be the following in tensorial notations as:

\section{Continuity Equation}

$$
\frac{\partial}{\partial x_{i}}\left(u_{i}\right)=0
$$

\section{Momentum Equation}

$\frac{D}{D t}\left(\rho u_{i}\right)=-\frac{\partial p}{\partial x_{i}}+\frac{\partial}{\partial x_{j}}\left[\mu\left(\frac{\partial u_{i}}{\partial x_{j}}+\frac{\partial u_{j}}{\partial x_{i}}\right)\right]+\left(\rho-\rho_{\infty}\right) g_{i}(2)$

$\mathrm{p}$ in Eqn.(2) is a modified pressure defined as $p=p_{s}+\rho_{\infty} g z$, where $\mathrm{p}_{\mathrm{s}}$ is the static pressure in the fluid domain. $\mathrm{p}$ in the domain will vary since $\rho$ is a function of temperature in the buoyancy term (else where it is constant).

\section{Energy equation in fluid}

$$
\frac{D}{D t}\left(\rho c_{p} T\right)=\frac{\partial}{\partial x_{i}}\left(k \frac{\partial T}{\partial x_{i}}\right)
$$

\section{Energy equation in fin}

$$
\frac{\partial}{\partial x_{i}}\left(\frac{\partial T}{\partial x_{i}}\right)=0
$$

\section{Boundary Conditions}

The boundary conditions for the solutions of Equations (1), (2) and (3) are shown pictorially in Fig. 2.

\section{At the wall (Heated plate)}

All velocity components are zero and, $T=T_{w}$

\section{At the inlet}

$U=0, \quad \mathrm{~V}=0, \quad$ and $\mathrm{T}=\mathrm{T}_{\infty}$

\section{At the pressure outlet boundary Top pressure outlet}

$\mathrm{P}=0, \mathrm{~V}$ determined from local pressure field and $\mathrm{U}$ found out to satisfy continuity equation, $\frac{\partial T}{\partial y}=0$, On the pressure outlet boundary the flow can come in to the domain or can go out of the domain depending on the local pressure field. The velocity perpendicular to the boundary can be computed from pressure conditions and a realistic flow field can be established through this boundary condition. Other boundary conditions can not be applied to a boundary where the flow either goes out of the domain or comes in to the domain.

\section{Side pressure outlet}

$P=0, \mathrm{U}$ determined from local pressure field and $\mathrm{V}$ found out to satisfy continuity equation (Dash, 1996), either $T=T_{\infty}$ or $\frac{\partial T}{\partial x}=0$ could be used.

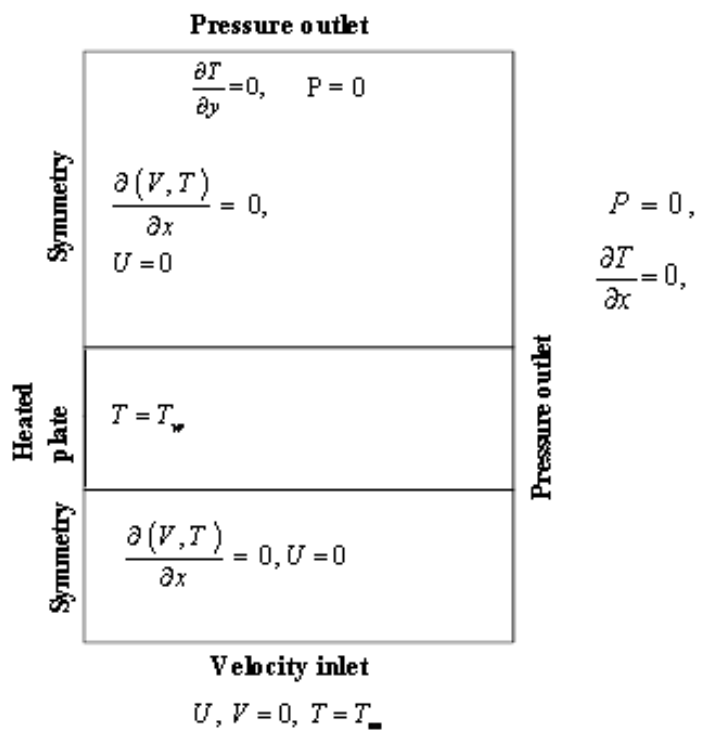

Fig. 2 Boundary conditions

\section{At the symmetry boundary}

$$
\frac{\partial(V, T)}{\partial x}=0 \text { and } U=0
$$

\section{At the fin}

The base of the fin is having a known temperature of $T_{w}$ at $x$ $=0$. At $\mathrm{x}=\mathrm{H} ;-\mathrm{kdT} / \mathrm{dx}=$ heat lost to surrounding fluid which is taken care of by the fluid flow near the adjacent cell at the tip of the fin. Near the surface $y=y_{0}$, and $y_{1}$ the heat lost by conduction from the fin is convected to the 
ambient fluid. So, the specification of heat transfer coefficient is not required at the fin surfaces which are taken care of by the fluid flow and energy equation through a conjugate heat transfer mechanism. For a non-conductive fin the surfaces of the fin are assumed to be adiabatic since no heat flow occurs from the fin to the ambient.

\section{NUMERICAL SOLUTION PROCEDURE}

Two-dimensional equations of mass, momentum and energy have been integrated over the control volume and the subsequent equations have been discretized over the control volume using the finite volume technique to yield a set of algebraic equations which could be solved by the algebraic multi grid solver of Fluent $\mathbf{6 . 3}$ in an iterative manner by imposing the above boundary conditions. First order upwind scheme (for convective variables) was considered for the momentum as well as for the discretized equations of energy. After a first-hand converged solution could be obtained (with 4363 cells) the grids near the plate and fins were adopted to half of its size (total cells $=12688$ ), the cell dimension was made half in both the directions so that the numerical errors can reduce very much, and the solution process was again made to converge where it was seen that the average Nusselt number only changed by $0.5 \%$. Then a second round of refinement in grids were done near the plate and fins which could result in 27712 cells in total and the average Nusselt number changed only by $0.1 \%$. Then a second order upwind scheme was adopted for the final convergence of the equations where the average Nusselt number hardly changed. This average value is reported and has been used for the correlation to predict the Nusselt number as a function of many different fin configurations.

Semi-Implicit Method for the Pressure Linked Equations (SIMPLE) algorithm with a PREssure STaggering Option (PRESTO) scheme for the pressure interpolation (to find cell face pressure from cell center pressure) was used for the pressure correction equation. Under relaxation factors of 0.3 for pressure, 0.7 for momentum and 1 for energy were used for the convergence of all the variables. Rectangular cells were used for the entire computational domain for rectangular fins. The cells were also mostly rectangular for the inclined fins but they were paved at the plate because it was the only choice in such a geometry. There were few triangular cells near the tip of the inclined fins, but they did not pose any convergence problem. Convergence of the discretized equations were said to have been achieved when the whole field residual for all the variables fell below $10^{-3}$ for $\mathrm{u}, \mathrm{v}$, and $\mathrm{p}$ (since these are non-linear equations) whereas for energy the residual level was kept at $10^{-6}$ ( energy being a linear equation).

\section{RESULTS AND DISCUSSIONS}

\section{Grid Independence Study}

In the numerical solution procedure we have outlined the grid sensitivity of the solution process. In Fig. 3 the average Nusselt number of the plate with three fins have been shown as a function of grid refinement or number of cells. The three fins were having different heights of 2, 4, 6 and 8 times of their thickness with a $\mathrm{P} / \mathrm{L}=0.25$. The fins are at $90^{\circ}$ to the plate and the average Nusselt number sharply increases with the change in grids (cells becoming smaller). After a cell of 20000 the average Nusselt number increases very slowly and there is practically no change in the Nusselt number when the total cells increased from 27712 to 45 552. For our computation we chose roughly a total number of cells around 30000 which gives pretty accurate Nusselt number.

\section{A Comparison of Average Nusselt Number with Similar Experimental Correlations}

The study on grid independence has been discussed in the last section. From the results obtained in the last section it can be told that the numerical simulation can be accurate provided one adopts a suitable grid resolution near the plate and chooses a right external domain. However it is always a good practice to match the result with available experiments or with experimental correlations. There are a number of experimental correlations for a vertical flat plate which describes the local Nusselt number as a function of Prandtl number and Grashof number and can predict the average Nusselt number. The local Nusselt number for the un-finned plate was matching extremely well with the given correlation of Eckert (1950) as shown in Fig. 4. So a good degree of confidence can be attached to the present computation about its accuracy, taking the uncertainty of the experimental correlations in to account.

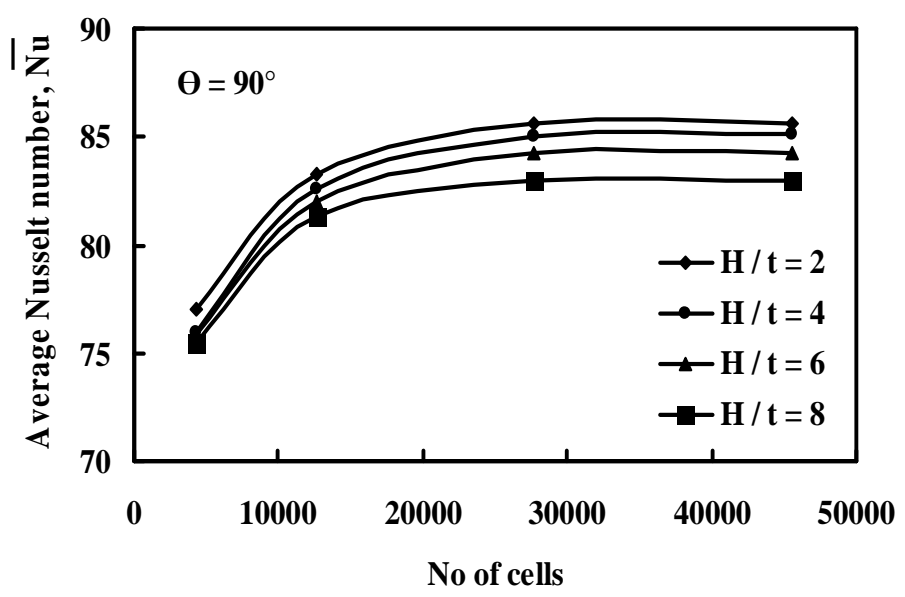

Fig. 3 Average Nusselt number as a function of the grid size with three fins of height, $\mathrm{H}=6,12,18$ and $24 \mathrm{~mm}$ with $\mathrm{P} / \mathrm{L}=0.25$. 


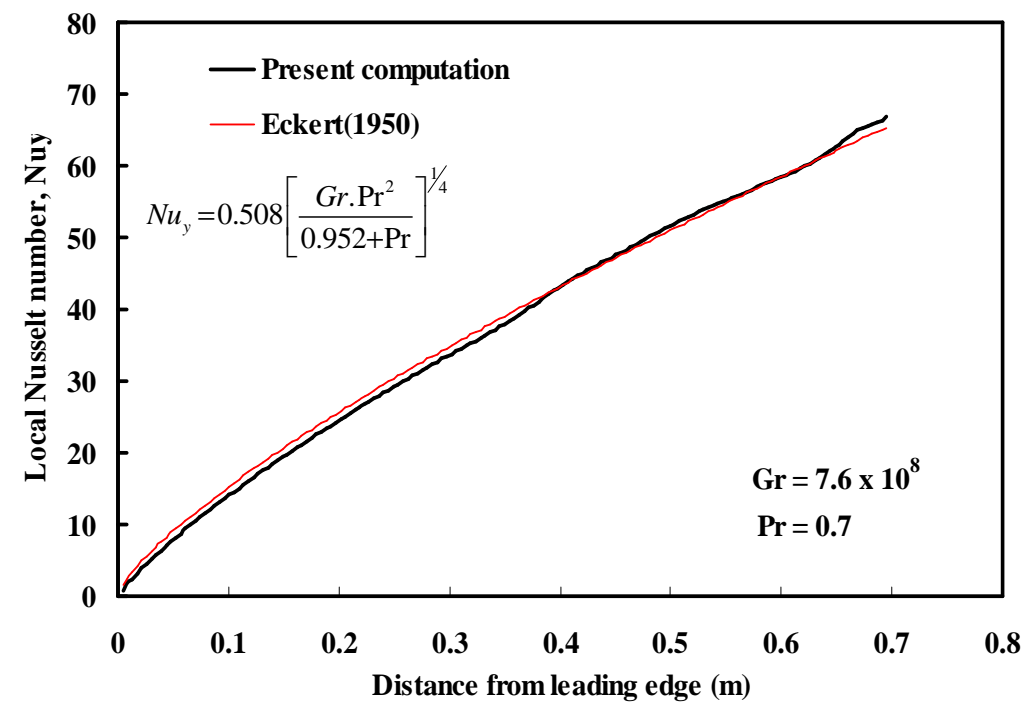

Fig. 4 Comparison of local Nusselt number between the present computation and the correlation of Eckert (1950).

\section{Flow Field near the Plate with Different Fins}

Fig. 5 shows the streamline patterns near the heated vertical flat plate with different fins. Fig.5 (a) shows a $6 \mathrm{~mm}$ high fin where the ambient fluid diverts a bit from its straight path and then again attaches to the vertical plate. Due to the reattachment the local Nusselt number on the plate rises a bit. When the fin height is $24 \mathrm{~mm}(\mathrm{H} / \mathrm{t}=8)$ the stream of fluid diverts much away from the plate and reattaches to the plate at a higher length compared to the case of the fin having a height of only 6 $\mathrm{mm}$. Due to a large deflection of the stream in to the ambient, the stream gets cold air from the ambient which reattaches to the plate thus increasing the local Nusselt number on the plate in the un-finned portion. Fig.5(c) shows the streamline pattern of the fluid near the plate having fins of $24 \mathrm{~mm}$ height but inclined at an angle of $45^{\circ}$. Here, the stream does not get deflected much in to the ambient but the reattachment length of the diverted stream is longer compared to the case of a straight fin shown in Fig.5 (b). Due to a relatively longer reattachment length (the wall shear stress on the heated plate increases from negative value to positive just after the fin. The stress increases to a maximum and then falls to zero again before the next fin and then again becomes negative. The length of the plate from zero stress to another zero stress is normally called the reattachment length between two successive fins.
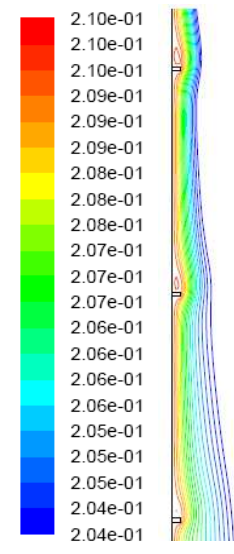

$\mathrm{kg} / \mathrm{s}$
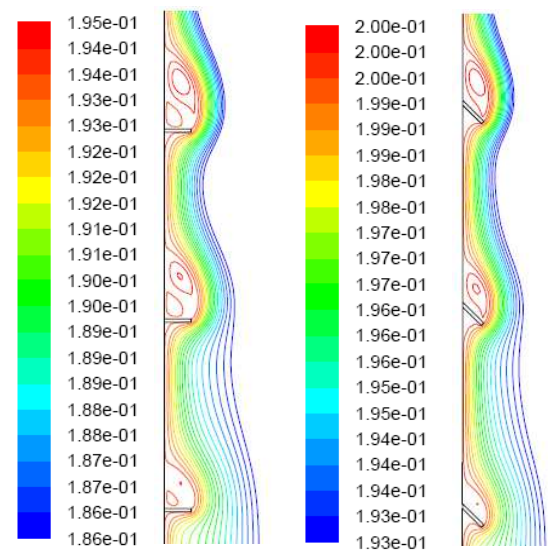

$\mathrm{kg} / \mathrm{s}$

$\mathrm{kg} / \mathrm{s}$

Fig. 5 Streamlines near the isothermal plate with different fin configurations (a) $\mathrm{H} / \mathrm{t}=2$, (b) $\mathrm{H} / \mathrm{t}=$ $8 ; \theta=90^{\circ}$, (c) $\mathrm{H} / \mathrm{t}=8 ; \theta=45^{\circ}$

\section{Variation of the Local Nusselt Number with Conductive Fins}

Fig.6(a) and 6(b) show the variation of local Nusselt numbers on the plate when $\mathrm{H} / \mathrm{t}$ varies from 2 to 8 (fin height varies from 6 to $24 \mathrm{~mm})$. The fins are conductive $(\mathrm{k}=219 \mathrm{~W} / \mathrm{m}-\mathrm{K})$ and straight. At the fin base the local Nusselt number shoots up sharply and it can be marked that there are three fins on the plate. The local Nusselt number on a plain flat vertical plate (without fins) is also shown on the same plot for a relative comparison between the two cases. The local Nusselt number in the un-finned portion (inter-fin portion) is higher compared to that of the same location for a plain flat vertical plate due to the reattachment of the newly drawn ambient fluid. Just near the fin base the local Nusselt number is lower compared to an un-finned case because the convection around the fin base is poor due to the obstruction created by the fin to the rising fluid stream.

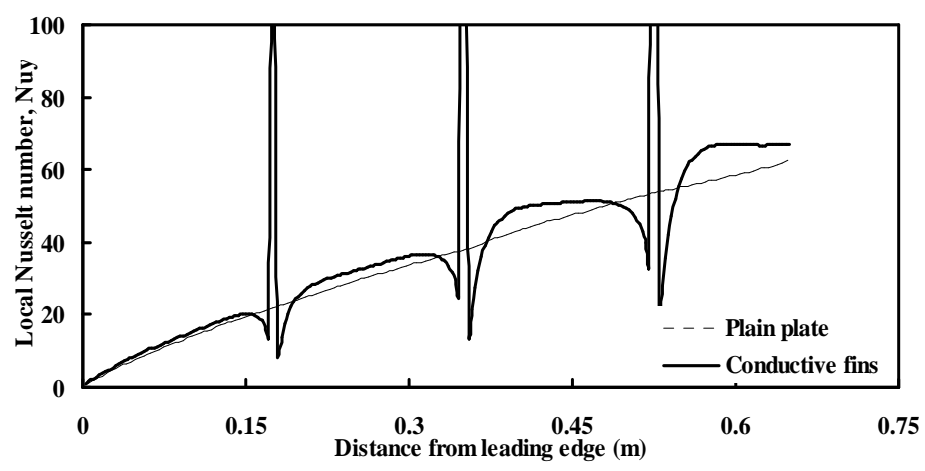

(a) 


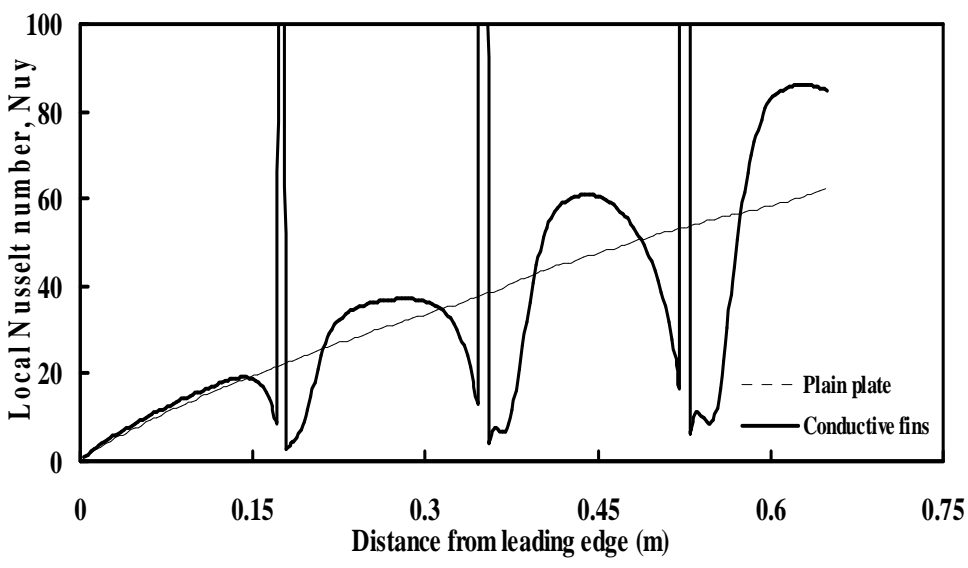

(b)

Fig. 6 Local Nusselt number distribution along a vertical plate with conductive fins (a) $\mathrm{H} / \mathrm{t}=2$ and (b) $\mathrm{H} / \mathrm{t}=8 ; \mathrm{P} / \mathrm{L}=0.25$, $\theta=90^{\circ}$.

For both the case of $\mathrm{H} / \mathrm{t}=2$ and 8 the average Nusselt number for the plate will be higher compared to the case of a plain plate. So there is certainly advantage in keeping the fins on the plate.

\section{Variation of the Local Nusselt Number with Non- Conductive Fins}

Fig.7 shows the local Nusselt number distribution on the vertical isothermal plate with three non-conductive fins having heights of $12 \mathrm{~mm}$ each $\mathrm{P} / \mathrm{L}=0.25$. The average Nusselt number for the plain plate is 80.9 whereas for the plate with 3 non-conductive fins the average Nusselt number is 85.06. At the base of the non-conductive fins there is no heat transfer from the plate to the fin or to the ambient since conductivity of the fin is assumed to be zero. So the local Nusselt number will be zero there which can be seen from Fig.7. But in the interfin space the local Nusselt number rises compared to the same location on a plain vertical plate as a result the average Nusselt number remains higher compared to a plain plate. Normally a common man thinks fins must be conductive so that they can serve as an extended heat transfer surface which can increase the net heat lost from the surface. But, here we are using nonconductive fins which do not take away any heat from the surface but still helps to increase the net heat lost from the surface. This happens due to the breaking of the boundary layer on the vertical flat surface created by the fins. Nonconductive fins are some time very helpful if it is wanted to increase the heat loss from a vertical plate heat exchanger very quickly. One has to just glue some non-conductive thermocoals (packing material used in computers) to the vertical plate. If it is wanted to increase the heat loss by a certain factor then one has to follow the correlations developed here. Fixing non-conductive fins are very easy compared to conductive fins because conductive fins are essentially metals and have high weight which can not be stuck to the metal plate heat exchanger so easily.

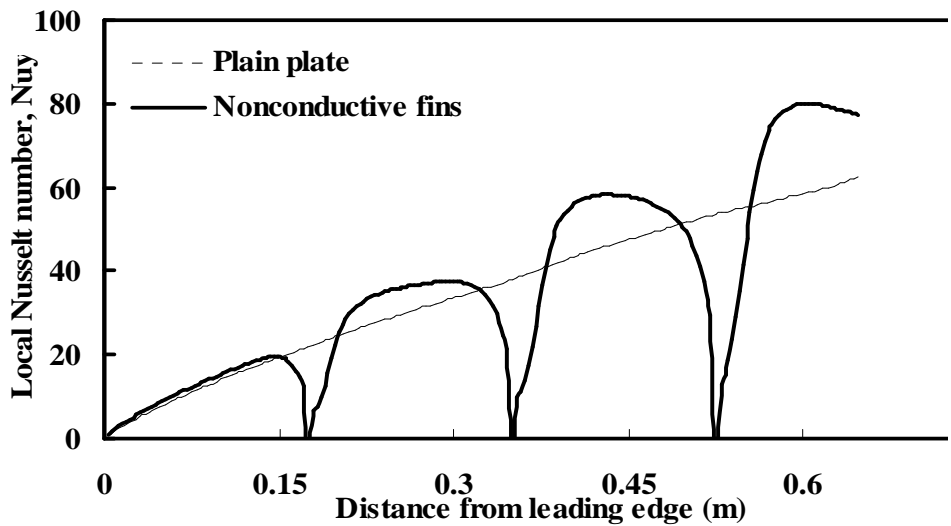

Fig. 7 Local Nusselt number distribution on the vertical isothermal plate with three non-conductive fins having $\mathrm{H} / \mathrm{t}$ $=4, \mathrm{P} / \mathrm{L}=0.25$, and $\Theta=90^{\circ}$

\section{Variation of Average Nusselt Number with Fin Spacing (Conductive Fins)}

Figure 8 shows the variation of the average Nusselt number for the plate with different fin spacing and varying inclination of the fins. The average Nusselt number rises with increasing fin spacing, attaining a maximum value of 97.64 at $\mathrm{P} / \mathrm{L}=0.2$ at $\theta=60^{\circ}$. It then decreases slowly as the fin spacing continues to increase. As the fin spacing rises there will be less number of fins on the plate and the reattachment length of the stream will be longer causing the local Nusselt number to be less and hence the average Nusselt number will fall. For a particular fin spacing the average Nusselt number can attain a maximum value which can be told to be the optimum fin spacing. In Fig. 8 the average Nusselt number is plotted with the inclination of the fins and it can be seen that there exists an optimum inclination of the fins $\left(60^{\circ}\right)$ to get highest average Nusselt number. When the inclination of the fins change, the flow around the fin gets deflected and tries to glide along the vertical plate so the reattachment length of the stream changes on the plate. The reattached fluid stream can withdraw different amount of heat from the plate, depending on its length, thus causing the average Nusselt number for the plate to change with the inclination of the fin and hence highest average Nusselt number can be obtained for a particular inclination of the fin.

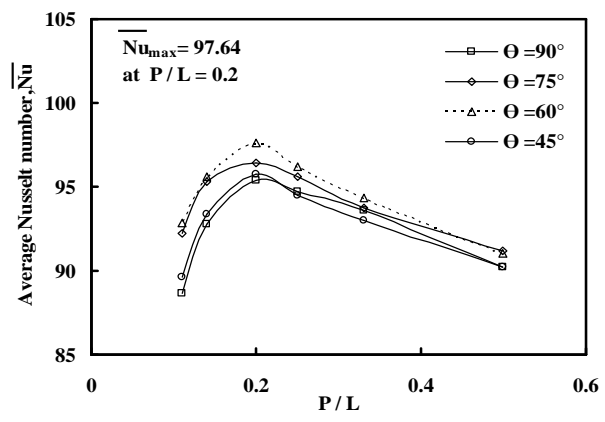

Fig. 8 Effect of fin spacing on average Nusselt number for aspect ratio of $\mathrm{H} / \mathrm{t}=6$ (conductive fins) 


\section{Variation of Average Nusselt Number with Fin Spacing (Non-Conductive Fins)}

The variation of average Nusselt number for the plate with non-conductive fins is very much different from that of the conductive fins. In Fig. 8 the average Nusselt number is shown as a function of P/L for conductive fins and in Fig. 9 the same variation is shown for non-conductive fins (although for $\mathrm{H} / \mathrm{t}=$ 8 but a plot for $\mathrm{H} / \mathrm{t}=6$ shows exactly the same trend but different numerical values). The two figures are very much different from each other. There is a maxima in the average Nusselt number with the conductive fins where as for nonconductive fins the average Nusselt number increases with fin spacing and attains a constant value after $\mathrm{P} / \mathrm{L}=0.33$. The inclination of the fins have probably less effect on the average Nusselt number compared to the case of conductive fins where the fin inclination have an appreciable effect on average Nusselt number. However, the maximum of the average Nusselt number for the plate could go up to 89.30 against the value of 80.90 for the case of plain plate with no fins.

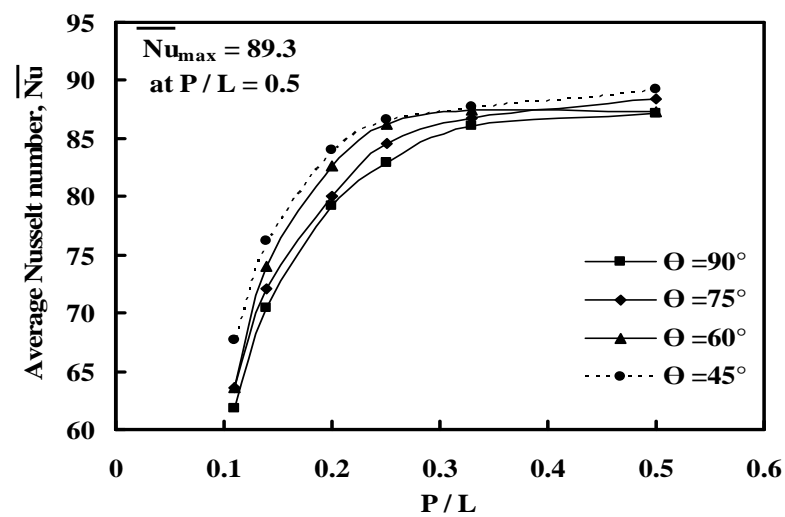

Fig. 9 Effect of fin spacing on average Nusselt number of the plate with non-conductive fins, $\mathrm{H} / \mathrm{t}=8$.

\section{Development of a New Correlation for Average Nusselt}

\section{Number}

For the two dimensional simulation of the present numerical study, an empirical correlation for the average Nusselt number is developed for the vertical isothermal plate with conductive and nonconductive fins based on the present computation. For the case of conductive fins there are a total of 96 computed data points (average Nusselt number) and similarly for the case of non-conductive fins there are also 96 computed data points. The objective is to bring out a correlation for the average Nusselt number which is a function of $\mathrm{P} / \mathrm{L}, \mathrm{H} / \mathrm{t}$ and $\theta$ of the fin. The Prandtl number is constant at 0.7 and the Grashof number can be up to a maximum of $10^{8}$ so that the value of $\overline{N u}_{p p}$ can be determined from some other correlation for a plain plate without fins. Such a correlation will be useful for the actual industry.
Eq. (8) shows the predicted Nusselt number for a plate with fins as a function of different fin configurations. $\overline{N u}_{p p}$ is the average Nusselt number for the plain plate without any fins. The right hand side term next to $\overline{N u}_{p p}$ is the augmentation factor which is determined from this study.

$\overline{N u}_{\mathrm{Pr} e d}=\overline{N u}_{P P}\left[\frac{\left(a+b \theta+c \theta^{2}\right)\left\{d+e\left(\frac{P}{L}\right)+f\left(\frac{P}{L}\right)^{2}\right\}}{g+\left(\frac{H}{t}\right)^{h}}\right]$

Range of $\theta=\pi / 4$ to $\pi / 2, P / L=0.5$ to 0.11 and $H / t=2$ to 8 for which Eq. (8) can be used for laminar natural convection.

It can be seen from Eq. (8) that the dependence of the average Nusselt number is quadratic on $\theta$ and $\mathrm{P} / \mathrm{L}$ and logarithmic on $\mathrm{H} / \mathrm{t}$. The average Nusselt number for the conductive fins has a maxima against the variable $\theta$ and $\mathrm{P} / \mathrm{L}$ so a quadratic dependence on these variables have been used in the correlation. The constants a, b, c, d, e, f, g, and h are tabulated in the table 1 . The present correlation gives a very good numerical match with the present computed CFD result. For the conductive fins all the predicted data points fall within an error limit of $5 \%$ (CFD $\overline{N u}$ is the base). For the nonconductive fins Eq. (8) predicts the $\overline{N u}$ to an error limit of $5 \%$ for 92 data points, whereas for only 4 data points the error goes to a maximum of $9 \%$. Eq. (8) has been developed from the Engineering Equation Solvers (EES) software with our present CFD result. EES helps tremendously to develop such complicated correlations very easily.

Table 1 The constants of Eq. (8)

\begin{tabular}{|c|c|c|}
\hline Coefficients & Conductive fins & $\begin{array}{c}\text { Non-conductive } \\
\text { fins }\end{array}$ \\
\hline $\mathrm{a}$ & 1.298 & 1.877 \\
\hline $\mathrm{b}$ & 0.439 & 0.154 \\
\hline $\mathrm{c}$ & -0.186 & -0.099 \\
\hline $\mathrm{d}$ & 1.271 & 0.748 \\
\hline $\mathrm{e}$ & 0.736 & 1.880 \\
\hline $\mathrm{f}$ & -1.298 & -2.426 \\
\hline $\mathrm{g}$ & 0.942 & 0.826 \\
\hline $\mathrm{h}$ & -0.081 & 0.063 \\
\hline
\end{tabular}




\section{CONCLUSION}

In the present study, the effects of fin geometry and the angle of inclination of the fins on the natural convection heat transfer from a vertical flat plate with fins have been investigated numerically. The most important results of the simulation are as follows.

(1) The maximum increase in the average Nusselt number for a conductive finned plate is around $20 \%$ as compared to a plain plate for the same operating conditions. This is obtained with pitch- to- length ratio $(\mathrm{P} / \mathrm{L})$ of 0.2 , fin height of $18 \mathrm{~mm}$, and angle of inclination of $60^{\circ}$.

(2) The maximum increase of the average Nusselt number for a non-conductive finned plate is observed to be around $10 \%$ as compared to a plain plate operating in similar conditions. This is obtained with a fin spacing of $P / L=0.5$, fin height of $24 \mathrm{~mm}$ and angle of inclination of $45^{\circ}$.

(3) A correlation is developed to predict the average Nusselt number of the plate as a function of fin spacing, aspect ratio of fins and its angle of inclination.

\section{REFERENCES}

[1] Starner, K. E., McManus, H. N. (1963), An experimental investigation of free-convection heat transfer from rectangular fin arrays, ASME Journal of Heat Transfer, Vol. 85, pp. 273-278.

[2] Welling, J. R. and Wooldridge, C. B. (1965), Free convection heat transfer coefficients from rectangular vertical fins, ASME Journal of Heat Transfer, Vol. 87, pp. 439-444.

[3] Harahap, F. and McManus, H. N. (1967), Natural convection heat transfer from horizontal rectangular fin arrays, ASME Journal of Heat Transfer, Vol. 89, No. 1, pp. 32-38.

[4] Jones, C. D. and Smith, L. F. (1970), Optimum arrangement of rectangular fins on horizontal surfaces for free-convection heat transfer, ASME Journal of Heat Transfer, Vol. 92, No. 1, pp. 6-10.

[5] Van de pol, D. W. and Tierney, J. K. (1974), Free convection heat transfer from vertical fin arrays, IEEE Trans. PHP-10(4), PP. 267-271.

[6] Bar-Cohen, A. (1979), Fin thickness for an optimized natural convection array of rectangular fins, ASME Journal of Heat Transfer, Vol. 101, No. 3, pp. 564-566.

[7] Sparrow, E. M. and Vemuri, S. B. (1985), Natural convection/radiation heat transfer from high populated pin fin arrays, ASME Journal of Heat Transfer, Vol. 107, No.1, pp. 190-197.

[8] Zografos, A. and Sunderland, J. E. (1990), Natural convection from pin fin arrays, Experimental Thermal and Fluid Science, Vol. 3, pp. 440-449.

[9] Aihara, T. and Maruyama, S. (1990), Free convection/radiative heat transfer from pin-fin arrays with a vertical base plate (general representation of heat transfer performance), International Journal of Heat and Mass Transfer, Vol. 33, No. 6, pp.12231232.

[10] Park, K., Choi, D. H. and Lee, K. S. (2004), Optimum design of plate heat exchanger with staggered pin fin arrays, Numer. Heat Transfer A \{4) pp. 347-361.

[11] Dash, S.K. (1996), Heat-line visualization in turbulent flow, International Journal of Numerical method for Heat and Fluid Flow, Vol. 6, No. 4,pp. 37-46.

[12] Eckert, E. R. G. (1950), Introduction to the Transfer of Heat and Mass, McGraw-Hill Book Company, First Edition. 